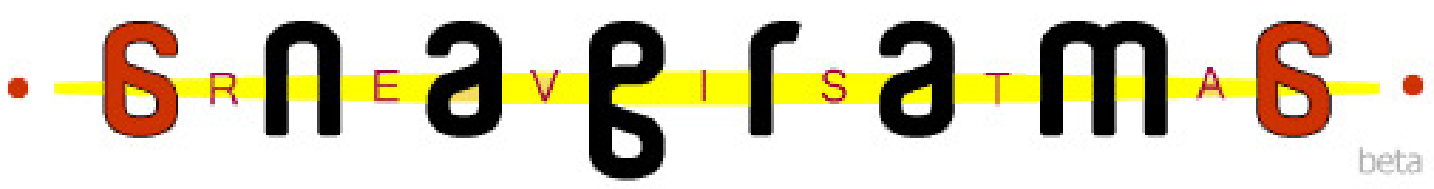

\section{Segmentação de mercado aplicada ao posicionamento estratéeico}

\author{
João Rodrigues Folharini ${ }^{1}$ \\ Rauany nunes Farias ${ }^{2}$
}

\section{Resumo}

Este trabalho apresenta o estudo e a análise realizados sobre o posicionamento estratégico de marketing, assim também como entrevistas feitas com profissionais de empresas de diferentes setores de mercado, através de um quadro comparativo de perguntas e respostas, para expor o que, de fato, se aproveita da teoria e é implementado na prática. Além disso, apresenta a bibliografia, o resumo, as citações e as referências utilizadas na constituição do estudo.

Palauras-chave: Posicionamento estratégico; Segmentação de mercado; Vantagem competitiva.

Este artigo tem como objetivo principal o entendimento da importância da segmentação de mercado no processo de posicionamento estratégico das marcas, sob a ótica da prática de profissionais do marketing de renomadas empresas de variados segmentos.

Para isso, foi realizado um profundo estudo dos resultados de entrevistas em profundidade com esses profissionais.

O levantamento teórico sobre o posicionamento estratégico de marketing está cada vez mais estruturado. Já se sabe que esse estudo é fundamental para empresas de pequeno, médio e grande porte, seja ela de qualquer segmento ou localidade geográfica.

$\mathrm{Na}$ teoria, toda empresa deve estudar e trabalhar seu posicionamento estratégico,

\footnotetext{
${ }^{1}$ Bacharel em Comunicação Social: Publicidade e Propaganda com Ênfase em Marketing - PUC-Campinas

${ }^{2}$ Bacharel em Comunicação Social: Publicidade e Propaganda com Ênfase em Marketing - PUC-Campinas
} 
explorando, dentro desse item, a segmentação de mercado e seu público alvo, aproveitando as vantagens competitivas que serão provenientes dos resultados desse trabalho.

Por outro lado, é necessário saber, o que, de fato, acontece na prática. Com estudos, análises e pesquisas realizadas com diferentes ramos empresariais, é possível identificar os principais pontos em potencialidade para estimular e desenvolver o processo de estruturação de marketing e sua aplicação a cada tipo de empresa, sendo, portanto, um estudo necessário para todas as marcas que buscam consolidar seu posicionamento com eficiência e resultado.

Entretanto, nem tudo o que está na teoria pode ser aplicado a todas as empresas. Para avaliar o que pode ser posto em prática e a maneira mais eficiente para isso em cada caso, é necessário que as empresas tenham total domínio das características de microambiente e de macroambiente que influenciam o seu negócio. Todos os fatores influenciadores devem ser analisados com cautela, pois o sucesso do desenvolvimento do posicionamento dependerá da coesão das informações provenientes dessa análise.

Portanto, para a realização de um estudo aprofundado desse processo, foram realizadas entrevistas com alguns renomados profissionais do mercado, as quais tratavam da importância da segmentação de mercado e do valor da marca, aplicados ao posicionamento estratégico, dentro das características de cada uma de suas empresas.

Os profissionais entrevistados foram:

Sr. Élcio Damaceno - 3M

Sra. Sílvia Prado - Consultora de Marketing

Sra. Elaine El Badouy Cecchettini (Badú) - Sony

Sr. Ronaldo Pinto Flor - Multibrás

Cada entrevistado abordou a visão da empresa a qual representa sobre a teoria do posicionamento estratégico de marketing e, também, da segmentação de mercado, de modo a fazer o cruzamento dessas informações e sua aplicabilidade dentro de cada situação.

Como base para o estudo dessas entrevistas, foram analisados e avaliados dois importantes embasamentos teóricos de marketing, possibilitando o domínio mais eficiente sobre as técnicas discutidas e sua aplicabilidade.

O primeiro diz respeito à teoria da essência do posicionamento estratégico.

Segundo Porter, se tratando de posicionamento estratégico de marketing, as empresas devem ser flexíveis para atender de maneira rápida e efetiva às alterações competitivas do mercado e não perder espaço. É através do benchmarketing (comparação 
com concorrentes) e do core competences (competências centrais) que uma empresa fortalece seu posicionamento e se mantém líder de mercado, precavida para diversas ameaças.

Atualmente, em muitas marcas, o posicionamento estratégico ainda pode ser considerado muito estático perante as variadas transformações do mercado, sendo comum encontrarmos empresas copiando o posicionamento das rivais, ao invés de desenvolver seu próprio posicionamento a partir de estudos que analisem a potencialidade de possíveis posicionamentos. Sem esse planejamento, o posicionamento criado provavelmente terá efeito por curto prazo e suas vantagens competitivas não serão duradouras.

Outra linha de análise teórica muito pertinente para a consolidação deste artigo é a definição de segmentação de mercado, segundo Kotler.

Ele afirma que a segmentação de mercado é fundamentada por um vasto grupo de compradores identificáveis em um mercado. A grande massa de consumidores difere-se em características físicas ou psicográficas, como, por exemplo, faixa etária, sexo, poder de compra, desejos, localizações geográficas, hábitos de compra, atitudes, entre outros. Sabendo essas informações, cabe às empresas a tarefa de isolar determinados grupos que apresentam características semelhantes, agrupando-os em diferentes categorias de público alvo e direcionar sua comunicação de maneira específica para cada um deles, efetivando sua estratégia de vendas de acordo com as características do produto ou serviço oferecido.

O cruzamento de informações desses dois conceitos com a análise em profundidade das entrevistas possibilitou o entendimento sobre a teoria da segmentação de mercado e suas diversas formas de aplicação na prática do posicionamento estratégico, de acordo com as variáveis de microambiente e de macroambiente de cada empresa.

\section{Segmentação de Mercado Aplicada ao Posicionamento Estratégico}

Posicionar estrategicamente uma empresa deixou de ser opção para ser obrigação de marketing há algum tempo. Para que esse posicionamento ocorra com coerência e eficácia, uma ferramenta comumente buscada é a segmentação de mercado.

A segmentação de mercado é uma ferramenta que possibilita o direcionamento do foco da comunicação de uma empresa para seus diversos tipos de consumidor. A quantidade de tipos de consumidor que a empresa vai ter pode depender tanto da quantidade e do tipo de cada produto e serviço que oferece, quanto do planejamento e das estratégias 
de marketing, que vão interferir nas características do target de acordo com a visão da empresa. Quanto mais amplo for o público alvo que a empresa deseja impactar, maior e mais complexo será o trabalho de segmentação.

O processo de segmentação de target pode ser importantíssimo para as estratégias da empresa, porém, para iniciar esse processo, é preciso ter uma série de conhecimentos básicos que influirão diretamente em seu estudo.

O primeiro conhecimento fundamental que será necessário é o conhecimento do mercado no qual sua empresa está inserida. Os profissionais que vão fazer esse trabalho devem ter total domínio e entendimento sobre as condições de macroambiente e também sobre as condições de microambiente influentes no processo.

Diferente do que grande parte das empresas faz, entender o mercado no qual está inserido demanda tempo, investimento e profissionais altamente qualificados, dificultando a aplicação desse estudo para as empresas menores. Além disso, não basta apenas levantar o histórico e todos os fatores que podem influenciar em seu negócio, como também é necessário ter uma equipe dedicada a fazer o acompanhamento da evolução desse mercado, permitindo a captação das novidades e a antecipação a qualquer empecilho que possa surgir no caminho. O mercado tem evoluído mais rápido a cada dia e as novidades, principalmente no campo do marketing, são atualizadas ainda com maior frequência, exigindo total atenção dos profissionais que farão seu acompanhamento.

Havendo esse domínio, a segmentação de mercado pode ser feita de diversas maneiras, de acordo com a cultura, com o mercado e com as condições de cada uma. Segmentar seu público alvo pode ser feito através de pesquisas de fonte primária (de cunho demográfico ou psicográfico), através de pesquisas de fonte secundária (através de institutos como IBGE ou Datafolha, por exemplo) ou, simplesmente, através de matrizes com informações provenientes do conhecimento e do acompanhamento dos funcionários responsáveis, que normalmente serão os diretores e aqueles que assumem os cargos de maior hierarquia dentro do marketing da empresa. O importante nesse momento é saber definir com clareza o perfil de seu target. Se esse trabalho não for feito com o devido estudo, atenção e fontes seguras, ele pode gerar imprevistos, que acarretarão em drásticos problemas de marketing, que serão percebidos no impacto sobre as vendas da empresa. Por não haverem ferramentas seguras sobre o controle da eficiência do posicionamento estratégico, muitos profissionais se enganam e não percebem a real efetividade de seu trabalho, em meio aos demais fatores que movimentam a empresa. 
A partir do momento em que se têm seus diversos targets devidamente definidos, já é possível notarmos a vantagem competitiva dessa segmentação. As informações que temos em nossas mãos, além de nos passarem as características específicas de cada público, podem também nos passar caminhos e estratégias para batermos nossos objetivos e isso também pode ocorrer através de diversas maneiras.

A primeira maneira diz respeito à distribuição. Com produto e target bem definidos em mãos, podemos especificar os melhores canais para se trabalhar. Esse trabalho engloba o estudo das mídias e dos canais passíveis de serem trabalhados, sobre a óptica da comparação de suas características com a dos diversos tipos de consumidor que se deseja impactar. Deve-se conhecer profundamente tanto as características demográfica, quanto as características psicográficas de seu target para que haja sinergia entre ele e os canais de distribuição selecionados. Esse trabalho permitirá o direcionamento mais eficiente das ações de comunicação para ele, criando, portanto, o primeiro grande diferencial competitivo da segmentação de mercado.

Atualmente, são poucas as empresas que trabalham com produtos/serviços voltados para um único público e a falta de segmentação desses consumidores pode acarretar em problemas no marketing, principalmente na mensagem que será transmitida para cada consumidor. Ao afunilar o público predominante dentro dos targets trabalhados, a segmentação exerce a importante função de definir as melhores estratégias de preço, direcionando-o para atender à classe econômica predominante dentro desse público. Portanto, além de ter completo domínio do mercado, a empresa precisa ter, também, completo domínio sobre as características de todos os possíveis targets, acompanhando sua evolução em comparação com a evolução da empresa.

O campo das estratégias de preço também é um campo muito complexo e dominado por poucos profissionais e empresas. O posicionamento estratégico geral da empresa, auxiliado pela segmentação de mercado, pode oferecer grande suporte nesse sentido, colaborando para o alcance da maior rentabilidade possível.

Essa ferramenta também pode oferecer suporte nas decisões sobre distribuição de conteúdo. A segmentação pode definir não só a mensagem, como o meio também. Não apenas o meio de distribuição do produto e do serviço, como também o meio de distribuição da comunicação.

É evidente que, através dela, haja maior eficiência no desenvolvimento de melhores estratégias nesse sentido. É preciso saber os locais em que cada um de seus consumidores 
está presente para encontrar o melhor caminho de distribuição, aumentando a efetividade das ações e, consequentemente, maximizando a verba investida. Sem a utilização do meio correto, a mensagem pode perder seu real sentido ou até comprometer e tornar confusa a comunicação da empresa.

A mensagem depende completamente do meio para sua efetividade e vice-versa.

O fato de nossa base ser constituída por entrevistas de profissionais presentes em variados tipos de segmento nos permitiu a comprovação da eficácia da segmentação no processo de posicionamento estratégico tanto no B2C, quanto no B2B. Independente do tipo de cliente com que se trabalha, a segmentação bem feita e bem estruturada sempre resultará em diferenciais competitivos.

Outro consenso em relação à segmentação é a questão de sua influência na relação com sua concorrência. Segmentar significa conhecer melhor o seu público. A empresa que segmenta seu mercado vai entender as percepções que seu consumidor tem tanto de sua marca, como também das marcas concorrentes e esse fator pode ser um poderoso diferencial competitivo para todo o território do marketing, passando por formulação de preço, promoção, trabalho em ponto de venda, campanha publicitária, canais de distribuição, etc..

É muito mais fácil entender a relação de sua marca com os concorrentes quando o mercado está fragmentado, do que quanto ele está compacto, como uma única peça. Com isso, as oportunidades de crescimento dentro de determinado segmento ficarão mais claras e facilitarão o foco da empresa.

Entender detalhadamente o posicionamento de seus concorrentes diretos e indiretos é tão importante quanto entender sua própria empresa ou seu próprio target.

Fica clara a importância da segmentação no processo de planejamento sobre público alvo, preço, mídias indicadas e distribuição, porém ainda há um campo muito complexo e aberto quando tratamos da influência da segmentação nos objetivos da empresa. Essa importância pode variar de acordo com diversos fatores, mas, principalmente com o segmento no qual essa empresa está inserida. A grande maioria das empresas que utiliza a segmentação de mercado, a utiliza como mais uma ferramenta para abrir caminhos que trilhem para seus objetivos, já traçados pela empresa em seu planejamento inicial.

Contudo, o que ainda não é visto como grande oportunidade é que, de acordo com os resultados obtidos por essa segmentação, é possível moldar e adaptar esses objetivos, buscando outros caminhos através de oportunidades que venham a surgir. Uma grande 
empresa não pode se fechar em seu planejamento inicial, ela deve ser flexível e estar aberta à todas as novas influências imprevistas que podem surgir, tanto positivas, quanto negativas, para, dessa maneira, estar sempre um passo à frente.

Conhecendo nosso target a fundo e sabendo quais são os canais mais eficientes para a comunicação com ele, devemos saber qual mensagem devemos passar. Todo produto ou serviço tem características positivas, mas que não são suficientes por si só. Elas devem ser transformadas, a partir do apoio da segmentação, em vantagem competitiva. Essa transformação será feita através da comunicação da empresa, que deve reforçar os pontos positivos que seu produto/serviço apresenta em relação aos concorrentes, de forma clara para fácil entendimento do consumidor.

Para que uma característica venha a ser uma vantagem competitiva, ela deve ser um benefício perceptível a todos os seus consumidores de forma concreta.

Por melhor que seja seu produto/serviço, se seu target não enxergar nele um benefício real, seu potencial será em vão e se perderá, sem espaço, em meio aos concorrentes, ou seja, o simples fato de ter um bom produto não é uma vantagem competitiva. Ele passará a ser essa vantagem quando o consumidor concordar com isso.

Por isso, para efetivar sua comunicação, é necessário que as características divulgadas do produto façam jus às necessidades desse consumidor. Ou seja, é preciso que, antes, sejam entendidas as carências do cliente, pois ele é o único que tem poder de avaliar uma característica como benefício ou não.

De acordo com a pesquisa realizada com grandes empresas, esse processo pode passar por um amplo trabalho chamado FFD (Feature Function Benefic). Além de analisar as características técnicas em relação às necessidades do consumidor, é preciso transformálas em vantagens competitivas e desprezar a sua real função. Dessa forma, é factível dar caráter único às vantagens. Dentro desse conceito, a real função do produto não tem importância, o que realmente importa é o benefício entendido e aceito pelo consumidor.

Com esse procedimento, é possível atingir de forma efetiva não somente o consumidor fiel, mas também estender a comunicação para um público mais abrangente, ampliando seu alcance dentro da segmentação de mercado trabalhada.

Com isso, fico fácil entender que quando a empresa tem a percepção e tem a sensibilidade sobre as carências e necessidades de seus consumidores, ela estará um passo à frente na busca por esse diferencial competitivo, se adiantando em relação aos concorrentes, que, por demorarem mais tempo para entender essas necessidades, perderão espaço no 
segmento.

Outro fator determinante na construção de uma análise intrínseca sobre posicionamento estratégico de marketing é a marca.

A cada dia mais valorizada e com maior poder, a marca é responsável pela determinação e significação de uma empresa no mercado. Para fins de qualificação, uma marca, atualmente, é capaz até mesmo de alavancar o valor das ações de uma empresa.

Mais do que isso, ela comunica ao mercado, de forma eficaz e rápida, todas as características e os valores dessa empresa, transcendendo o produto vendido. Fato que decorre não somente quando direcionado ao consumidor final, mas, também, voltado ao B2B, ou seja, não importa qual é o tipo de cliente com o qual sua empresa trabalha, a marca sempre exercerá importante poder de comunicação sobre ele.

A marca pode movimentar maior verba de uma empresa do que seu próprio patrimônio líquido. Isso ressalta ainda mais sua influência e importância. Portanto, no processo de posicionamento estratégico, a arquitetura da marca da empresa é um princípio fundamental para seu sucesso.

Sendo bem trabalhada, uma marca consolidada traz, também, vantagens competitivas para a empresa e seus produtos e serviços. No contexto mercadológico de massa populacional, é possível expor o que sua empresa busca, o que ela é e a qualidade de seu produto ou serviço para milhões de pessoas, bastando apresentar seu logotipo. O logotipo é a primeira impressão sobre a marca de uma empresa e, por isso, não basta ter o design bem trabalhado, seu conceito e a mensagem que ele passa são fundamentais para a fácil compreensão dessa marca. Basta olhar para as maiores empresas do mundo, para entender o poder conceitual que seus logotipos, que normalmente são simples e sofrem pouquíssimas alterações, exercem sobre seus consumidores.

Ainda se tratando de vantagem competitiva, todo o esforço da construção da comunicação dos produtos e da consolidação da marca, deve ser feito para expor ao consumidor que o produto/serviço vendido é único. Dessa forma, você está criando uma larga vantagem em relação aos concorrentes. A empresa consegue provar que o que oferece é único e especial a partir do momento no qual consegue provar os seus reais benefícios.

Para aumentar ainda mais a vantagem competitiva, é muito importante que a empresa seja focada no cliente e dê valor a ele, tenha qualidade de serviço/produto superior, ampla distribuição, técnicas de produção com baixos custos, patentes e direitos autorais, proteção do governo, funcionários capacitados e bem treinados, entre outros. Todos esses 
fatores, quando bem trabalhados, podem ser diferenciais influentes para a concretização de uma vantagem dentro do posicionamento estratégico da empresa, mas, para isso, a empresa deve primeiramente se entender.

Diferente do que muitos pensam, entender as características de sua própria empresa não é tão simples. O simples fato de estar dentro dela pode cegar o profissional para alguns pontos fundamentais dentro de sua constituição. Por isso, corriqueiramente, é necessário se ter uma visão de fora. O profissional responsável por essa tarefa deve se colocar como alguém que não conheça a empresa a fundo ou ainda contratar um profissional especializado nesse tipo de análise, que terá maior facilidade em entender esses aspectos, principalmente os negativos, pois, além de não ter uma visão ampla, o funcionário da empresa tende a defendê-la de qualquer tipo de acusação de defeito.

As entrevistas realizadas também demonstraram que os profissionais da área de marketing tendem a não criar diferenciações da estratégia de posicionamento de marcas em mercados segmentados distintamente. Tendo em vista que estratégia de marca tem o custo elevado e que os benefícios adquiridos nem sempre conseguem cobrir o investimento no mercado específico, é preferível centralizar todos os investimentos na marca/produto/serviço base. Além disso, a segmentação e a diferenciação podem misturar características e gerar marcas secundárias sem força de mercado, podendo interferir negativamente no desempenho da marca principal da empresa. É importante que a empresa seja sólida e seja focada em seu crescimento como um todo, tendo cautela ao pensar em arriscar a credibilidade de toda a marca em um segmento específico. A marca deve ter seu conceito claro e coerente.

Outra definição importante levantada em entrevista sobre segmentação de mercado é a possibilidade da criação de uma barreira contra os concorrentes, quando as estratégias de posicionamento de marcas atingem um grau elevado de especificidade com o públicoalvo.

Assim que a empresa consegue estipular uma relação por entender as necessidades mais intrínsecas do consumidor por consolidar uma segmentação bastante específica, esse consumidor tende a criar fidelidade com a marca, pois o produto/serviço/oferta foi montado pensando nele. Além de compreender a marca e de aceitar os benefícios do produto/serviço oferecido, ele precisa se sentir importante. O consumidor gosta de enxergar as empresas e suas ações de forma transparente e gosta de sentir que tem o poder, que a marca existe para te servir. 
Feito isso, a empresa conseguiu atingir um dos principais objetivos da vantagem mercadológica: ser única. Dessa forma, os concorrentes têm enorme dificuldade para competir nesse mercado, ou seja, foi criada uma barreira para outras empresas desenvolveram sua competição de mercado.

\section{Conclusão}

Fazendo um estudo de comparação entre embasamento teórico e entrevistas em profundidade com quatro profissionais atuantes em diferentes segmentos de mercado, notamos que, atualmente, já existe consenso em alguns aspectos que englobam o posicionamento estratégico. O poder e a influência de uma marca e a importância da segmentação de mercado na busca de caminhos para alcançar os objetivos da empresa já são fatos presentes no cotidiano das grandes empresas. Porém, o que ainda não está clara é a função dessa mesma segmentação de mercado para aplicação na elaboração de objetivos.

Muitas empresas, principalmente as mais tradicionais, são muito fechadas a alterações em seu cronograma inicial e seguem a qualquer custo o que foi planejado para se chegar aos objetivos previamente estipulados. Essas empresas utilizam a segmentação de mercado como ferramenta para otimizar sua comunicação com o target, alinhando formas de distribuição, conteúdo a ser disseminado, estratégia de preço e meios a serem trabalhados. Tudo em função de alcançar os objetivos que foram estabelecidos em um primeiro momento.

Acontece que, durante o processo de segmentação, essa ferramenta pode abrir novos caminhos, criar diferencias competitivos, apontar segmentos sobrecarregados e mostrar oportunidades.

Com a segmentação feita de forma correta, estruturada e por profissionais competentes, as informações que ela vai render podem ter potenciais não apenas de buscar os objetivos traçados, mas também de traçar novos objetivos. Como vimos, o estudo de segmentação de mercado alcança informações que antes não eram perceptíveis à empresa e, dentro dessas informações, podem estar contidos detalhes capazes de abrir uma oportunidade muito maior do que os objetivos almejados. Nesse caso, a empresa deve estar preparada e ser flexível à adaptação de suas metas, dando liberdade para outras formas de evolução.

Por outro lado, as empresas muito modernas e flexíveis devem tomar cuidado. Uma nova informação pode parecer inspiradora e revolucionária, surgindo como uma enorme 
oportunidade, mas nem sempre ela realmente será. Um pequeno deslize dentro desse estudo pode ser fatal e, por isso, deve-se ter enorme atenção ao segmentar seu mercado.

Uma nova informação, proveniente da segmentação de mercado, pode influenciar nos objetivos da empresa, porém, jamais poderá substituir todo o planejamento de marketing, feito anteriormente.

Este estudo, certamente, abre um amplo campo a ser explorado a partir de uma nova visão sobre a segmentação de mercado, mas apresenta algumas limitações. Para sua completa efetividade, é necessário trabalhar a segmentação junto a todos os outros fatores que influenciam dentro do processo de posicionamento estratégico de marketing.

Para isso, sugerimos ainda um estudo mais detalhado sobre alguns desses fatores, que são mais recentes e ainda de difícil compreensão e aplicação, como os novos variados tipos de vantagem competitiva, o real benefício de um produto ou serviço perante seu consumidor ou ainda o poder que uma marca exerce na definição do posicionamento estratégico de determinada empresa.

\section{Referências Bibliográficas}

PORTER, MICHAEL E. What is Strategy, Harvard Business Review, 1996.

KOTLER, P. Administração de Marketing, Prentice Hall, São Paulo, 2000.

JÚNIOR, CAETANO H. Segmentação de Marcas Fertilizantes por Estilo de Vida do Produtor Rural - Dissertação de Mestrado - UNIMEP, 2006. 